Eva Schultze-Berndt (Manchester) \& Dina El Zarka (Graz)

\title{
The semantics of Moroccan Arabic dar 'do' in typological perspective
}

\begin{abstract}
This paper is a case study in the exploration of the semantic range of single a high-frequency lexical item on the basis of a corpus of spoken language, in this case Moroccan Arabic. Generalised action verbs ('do' verbs) are an interesting object of study because cross-linguistically, they can exhibit a wide range of functions including that of causative verb, verb of creation, verb in agentive collocations, verbaliser with loan words and mimetic expressions, quotative verb, and even a copula-like use with property predicates (Schultze-Berndt 2008). Against this typological background, the range of functions of Moroccan Arabic dar 'do' is investigated.
\end{abstract}

Keywords: Moroccan Arabic, semantic maps, do-Verbs, copula function

\section{Introduction}

In this paper, we explore the range of functions of the 'do' verb dar in Moroccan Arabic (MA henceforth), based on a corpus of colloquial spoken MA (cf. MAAs \& ProcházKA, this volume). We employ a cross-linguistic perspective based on the semantic map of "do" verbs proposed by Schultze-Berndt (2008). At the same time, this is a case study in the possibilities but also the limitations of using a corpus for the study of the semantic range (as well as the syntactic distribution) of a single lexical item; the corpus-based research is, however, complemented by elicitation.

The basis for the investigation is the observation that all languages appear to have what Van Valin \& LaPolla (1997) term a Generalised Action Verb (GAV). A Generalised Action Verb is a verb such as English do (1), Japanese suru (2), or Kalam g- (3) which is used as 'pro-verb'. In other words, it appears in contexts where an actor - or more appropriately, an Effector (VAN VALIN \& WILKINS 1996) - brings about an event whose nature is unknown or left unspecified in the context, and which is represented by a pronominal or interrogative complement, as illustrated in the following examples.

(1) English

(1a) What did she do?

(1b) Who did this?

(1c) I already did it.

(2) Japanese

Jon-ga minna-ni sonna koto-o shita.

[Matsumoto 1996: 114]

John-NOM all-DAT such thing-ACC do:PST

'John did such a thing to everyone' 
In the literature, it is often assumed that generalised action verbs, i.e. translation equivalents of English 'do' and the corresponding verbs in the above examples, universally have a similar semantic range, and that their first argument is necessarily agentive in nature. It is for this reason that 'do' has come to be employed in proposals for the semantic decomposition of verb meanings representing either agentivity, or activity (in the Aktionsart sense), e.g. by Dowty (1979: 118), Foley \& VAn Valin (1984: 47-53), Wierzbicka (1996), and VAN VAlin \& LaPolla (1997: 102-129).

However, if one examines the functions of such verbs cross-linguistically, they turn out to occur in a wide range of constructions and expressions. While these include causative and agentive expressions, 'do' verbs do not necessarily entail agency or activity. Rather, depending on the language in question, a generalised action verb may also serve as a verbaliser with sound-symbolic elements ('go "pop"!'), as a quotation marker ('say “...”'), and even in inchoative expressions ('become $\mathrm{X}$ ') and expressions of manifestation of a property or quality ('be X'). As we will see, Moroccan Arabic dar covers a fairly wide range out of these cross-linguistically attested functions. The links between the different uses can be represented in a semantic map.

The remainder of this paper is structured as follows. In section 1, we introduce the Moroccan Arabic verb dar in its Generalised Action Verb use, with some information on its etymology. In section 2, we examine in detail the other uses of this verb, taking as a basis the attested semantic range of GAVs cross-linguistically. This survey is mainly based on available examples in a corpus of spoken colloquial Moroccan Arabic, mostly recorded in the Atlas region, but is complemented by results of a questionnaire investigation undertaken by SANDRA Ziagos, and direct speaker elicitation. In section 3, the findings will be summarised in the form of a semantic map based on the one proposed in ScHultzeBERNDT (2008).

\section{The generalised action verb in Moroccan Arabic}

In Moroccan Arabic the function of Generalised Action Verb is mostly associated with the verb dar 'do, make'; this use of dar is highly frequent and widely attested in the corpus. Some representative examples are provided in (4) to (7). As (6) and (7) show, an indirect object marked with the preposition $l(i)$ - can specify an entity affected by the action.

(4)

$\begin{array}{ll}\text { MA } & \\ \text { kif.a } & t \text {-dir- } u \\ \text { how } & \text { 2.IPF-do-P }\end{array}$

[A.04.10_0046] $]^{1}$

1 Examples taken from the Graz corpus of spoken Moroccan Arabic are referenced by the file name of the text, with four digits following an underline indicating the line number. English glosses and translations were added by the authors. Glosses of grammatical categories follow the conventions adopted in the glossing of the corpus and the papers in this issue. 
(5) MA
bdi-na$$
l-x ə d m-a
$$
$k v l^{\prime}-x \neq f a$
$\int . n u$
ka-n-dir
begin-1s.PF DF-work-Fs all-time what IND-1s.IPF-do

[A.04.4a_0088]

'We began the work, each time another type of work' (lit.: 'We began the work, each time what I do')

(6) MA

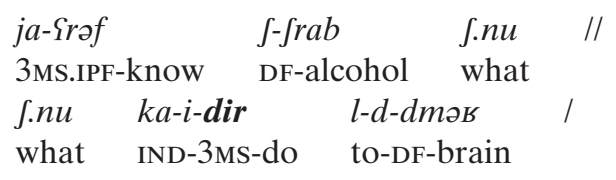

[A.06.3_0260-1]

'He knows what alcohol is, what it does to the brain'

(7) MA

ma i-dir-u-l-ək walu

NEG 3.IPF-do-P-to-2s nothing

[A.06.1_0056]

'They don’t do anything to you', i.e. 'they don’t harm you' (cf. German 'sie tun dir nichts')

Much less frequently than $d a r$, a second verb, $s ə w w ə b$, is used as translation equivalent of 'do' in the Moroccan Arabic corpus. An example of its use as a generalised action verb is (8). The example comes from direct speech imploring a potential candidate for upcoming elections to indeed put himself forward as a candidate.

$$
\begin{aligned}
& \text { MA } \\
& \text { u daba si(r) nud sow:a: } \boldsymbol{b} \\
& \text { and now just get.up:Imp. m make:Imp.ms } \\
& \text { 'And now just get up! Do it!' (Los jetzt! Kandidiere!) }
\end{aligned}
$$

(9) MA

$\begin{array}{lll}\text { ra } & \text { kajn // } & \text { sawb-i-li-ja } \\ \text { PRT } & \text { be:PCP.MS } & \text { make:IMP-FS-to-1s }\end{array}$

'There is (work), do it for me'

$\begin{array}{lll}u \quad t \text {-dir-i-li-ja } & \text { hadi } \\ \text { and } & \text { 2s.IPF-do-FS-to-1s } & \text { DM.FS } \\ \text { 'And you do this for me' } & \end{array}$

At a first glance it seems that both verbs in example (9) may be used interchangeably. However, while $s ə w w ə b$ may be used with or without a direct object, the direct object of dar has to be made explicit. Accordingly, it would be odd to use dar instead of səwwəb in (8).

The MA verb dar, idir 'make, do' is a simplex verb with the root $\sqrt{ } d j r$, which goes back to the Old Arabic root $\sqrt{ } d w r$ with the basic meaning of 'turn'. The simplex verb in Classical Arabic (CA) is da:ra, jadu:ru 'to turn (intrans.); make a turn', but there is a verb of the forth measure Pada:ra, judi:ru meaning 'to turn (trans.), twist; govern; operate', which most probably is etymologically related to MA dar, idir. The verb səwwəb (or sawb) is derived from the root $\sqrt{ } s w b$; its measure being a typical form for causative and denominal verbs in Modern Arabic dialects and in Modern Standard Arabic (MSA). The most frequent usage of the CA/MSA verb is in the meaning of 'aim, put in the direction of'. But as this measure is quite productive, the verb may also be a denominal formation from sawa: $b$ 'right', in the sense of 'make something right; do something to the effect that it be right'. 
Interestingly, the Arabic varieties make use of different 'do'-verbs for the function of generalised action verbs which have a basis in the heritage lexicon. Example (10) shows the semantically and pragmatically equivalent translations of 'What are you doing?' in three Arabic varieties:

(10a) Moroccan Arabic (MA):

?aj ka-t-dir

what IND-2S.IPF-do

(10b) Egyptian Arabic (EA)

bi-ti-smil ?e:

IND-2S.IPF-do what

(10c) Iraqi Arabic (IA)

Pe: $\quad$ da-t-sawwi

what ASP-2S.IPF-do

While the EA verb is a case of extending the function of the CA verb Samila, jaSmalu 'to work', the Eastern Arabic equivalent sawwa, jisawwi originally means 'make even, straighten; accommodate, adjust'.

\section{Functions of MA dar in a cross-linguistic perspective}

\subsection{Agentive collocations}

The function of $d a r$ 'do' which is arguably most closely related to the generalised action verb use is in combination with a direct object representing a more specific activity or task that is performed. In such expressions, the first argument is agentive.

$\begin{array}{lll}\text { dər-t } t \quad \text { biS.a } & \text { u } & \text { frij.a } \\ \text { do:PF-1s sale } & \text { and purchase } \\ \text { 'I did business.'/'I worked as a salesman.' }\end{array}$

(12) MA

la bia ma //

NEG father.MS NEG

ma вьа-f i-dir mia-ja had.l-hol:

NEG want:PF.3MS-NEG 3MS.IPF-do with-1s DM-solution

'No, my father didn't- he did not want to pursue this solution (lit: 'do this solution') with me'

(13) MA

$\begin{array}{llllll}\text { daba } & \text { ma.fi } & \text { dar- } t & l \text { - } \text { fors } & f \text {-d-đar } & \text { djal ... } \\ \text { now } & \text { NEG } & \text { do:PF-3.Fs } & \text { DF-wedding } & \text { in-DF-house } & \text { Poss } \\ \text { 'Now she did not have (lit. 'do') the wedding in the house of ...' }\end{array}$

[A.06.2_0444]

Although the N-V constructions are collocationally fixed - it is for instance not possible to use the other 'do'-verb səwwəb in the cited cases - the construction seems to be quite productive as far as the lexical filling of the object position is concerned. More examples will be given in section 2.5 which deals with dar in combination with loanwords.

An interesting - apparently also productive - modification of this construction contains an indirect object and a prepositional complement in place of the direct object, the pre- 
positional complement specifying the type of action and the indirect object the undergoer of the event. The idiomatic expression 'to cause problems for someone' in (13) could be modified as in (14) to add a nuance of exaggeration and emphasis to the basic meaning.

(14) MA

$\begin{array}{llll}x \text { u-ha dar-l-ha } & \text { l-mafakil } & \text { tom:a } \\ \text { brother-3Fs } & \text { do.PF.3MS-to-3Fs } & \text { DF-problem.P } & \text { there } \\ \text { 'Her brother caused problems for her there.' } & \end{array}$

[A.06.1_0566]

(15) MA

J.nu dar-l-ha b-l-majakil

[elicited]

what do:PF.3MS-to-3Fs with-DF-problem:P

'What problems he caused for her!' (lit: 'What he did to her with the problems!')

A similar example (15) can be found in the corpus. But while mafakil 'problems' in (15) - being a "proper" noun - in this case a definite count noun in the plural - constitutes a legitimate argument, the nominals in examples (15) and (16) are masdar forms (verbal nouns) and thus more apt to express actions. At the same time the 'do'-verb itself gradually loses its semantic content, developing into a mere function verb. The original meaning of 'doing something to someone' is still present when an affected participant is mentioned. We can read example (16) in the sense of "what he did to him by abusing him.

(16) MA

$\begin{array}{lll}\int . n u & \text { dar-l-u } & \text { b-s-sbran } \\ \text { what } & \text { do:PF.MS-to-3MS } & \text { with-DF-offence }\end{array}$

'How he offended him!' (lit: 'What he did to him with the offence!')

[A.06.1_0735]

While the preposition $b$ - 'with, by, through' is used in the above examples, with an indirect object present, to specify the action, a prepositional object with the preposition $f(i)$ 'in, about' is used to add semantic specificity to the general action that is performed when no indirect object is present. For example, in (17), the prepositional object expresses the idea that the actions of the agent involved (the family of the employer of the speaker) amount to wasting food or money.

(17) MA
$x ə s-ə k$
$t-\int u f-i-h v m$
?a)
dajr-in
$f$-t-tobdir
be.necessary:PF-2s
2-see.IPF-Fs-3P what
do.PCP-P in-DF-waste
'You should see how lavish they are' (lit.: 'You should see what they do in terms of wasting').

[C91.1_0579]

Finally, another way of expressing an activity with dar plus a prepositional complement makes use of the preposition $l$ - that is also used for indirect objects. In this case, the prepositional complement describes the action itself and consequently, the direct object is absent.

(18) MA (elicitation with AA)

(18a) dar l-xədm.a

do:PF.3Ms DF-work.FS

'he did the work'

(18b) dar l-l-xədm.a

do:PF.3Ms to-DF-work.Fs

'he worked a lot' 
(19) MA (elicitation with AA)

(19a) dar t-triq

do:PF.3Ms DF-way

'he went (from A to B)'

(19b) dar l-t-triq

do:PF.3ms to-DF-way

'he went a long way (from A to B)'

The prepositional constructions in the (b) examples of (18) and (19) add a notion of emphasis or quantification to the semantic content, whereas the direct object construction constitutes a detached factual statement.

\subsection{Creation}

'Do' verbs often have a meaning of "creation" or "manufacturing", with an effected object as their second argument. An example is German machen 'make', illustrated in (20) in both its generalised action verb and in its creation verb use.

(20) German

(20a) Was hast what AUX.PST:2s 2s yesterday make/do:PCP 'What did you do yesterday?'

Ich habe $\quad$ eine Laterne
1s Aemacht
'I made (i.e.created) a lantern'

The use of dar in a creation sense, at least judging on the available corpus examples, is fairly marginal, and usually, səwwəb is used in this function. Both verbs are attested in a food preparation context; however, (21) is the only instance of dar in such a context.

(21) MA

\begin{tabular}{|c|c|c|}
\hline $\begin{array}{ll}u & \boldsymbol{d} \boldsymbol{u} \boldsymbol{r}-t-u \\
\text { and } & \text { do:PF-1s-3MS }\end{array}$ & $\begin{array}{l}X X X \\
\text { [unintelligible] }\end{array}$ & $\begin{array}{l}\text { djal } \\
\text { POSS }\end{array}$ \\
\hline
\end{tabular}

[A.06.2_0583]

(22) MA

$$
\begin{array}{ll}
k-i-s \boldsymbol{a} \boldsymbol{w} \boldsymbol{b}-u & z \text {-zəmitia } \\
\text { IND-3-make-P } & \text { DF-Zemmita }
\end{array}
$$

'they make the Zemmita (a sweet dish made from flour)'

Similarly, both verbs are attested in the context of preparation of documents; compare (23) and (24) with (25). The occurrence of dar in (24) can however also be explained by the presence of the French borrowing futukopi, either as a calque of French faire une photocopie 'make a photocopy' or as a productive verbaliser with loan words (see section 3.5).

(23) MA

$$
\begin{array}{llcc}
\text { fa } \quad \text { dar-u-li-ja } & \text { l-iqam.a } & \text { tom:a } \\
\text { so do:3.PF-P-to-1s } & \text { DF-residence.permit.Fs } & \text { there } \\
\text { 'they made the residence permit for me there (so I could stay)' }
\end{array}
$$

[C.91.1_0260] 
(24) MA

$\begin{array}{llll}g a(l)-t-l-i & \text { sir // } & \text { dir } & \text { futukopi } \\ \text { say: PF.3S-F-to-1s } & \text { go:IMP.MS } & \text { do:IMP.MS } & \text { photocopie(Fr) }\end{array}$

[A.06.1_0406]

d-la.kart $u \quad \hbar \partial t(:) \quad$ tom:a

de-la.carte(Fr) and put:IMP.Ms there

'She told me "go, make a copy of your (ID) card and put (it) there""

(25) MA

$\begin{array}{lll}t \text {-sawəb-l-u } & \boldsymbol{l} \text {-uraq } & f \text {-l-blasa } \\ \text { 2s.IPF-make-to-3MS } & \text { DF-paper:P } & \text { in-DF-place }\end{array}$

'You make the papers for him at the place'

As a matter of fact, səwwəb (or sawb) is used to focus on the actual physical process of creation, while expressions with dar describe an entire procedure which may lead to the production of something. For example, dar futukopi is the translation equivalent of English 'photocopy' rather than expressing the creation of a document. Using səwwəb instead of dar in the photocopy-example would imply not a simple action of photocopying, but some special task, such as making a copy of part of the original only. Whereas səwwəb focuses on the action itself, dar indicates the outcome of such an action, as illustrated in example (26). Thus, dar is the more generally used of the two do-verbs, while səwwəb implies a specialized type of action.

(26) MA

f.hal $\quad$ ka-t-dir-u?
how.many $\quad$ IND-2.IPF-do-P
'How many do you make?'

[A.04.4a_0154]

The verb dar, furthermore, is attested in a more specific reading of 'make into something, transform', illustrated in (27) and (28). This may be linked to its 'transfer' use, discussed in the next section. These examples also nicely illustrates the difference between $d a r$ and $s ə w w ə b$, the latter only being possible in the literal sense of producing whatever is signified by the second argument.

(27) MA

[A.04.4a_0185-6]

(27a) f.hal

how.many

ka-t-dir- $u$

f-l-lil.a //

IND-2.IPF-do-P

djal

l-xənf.a-t

$d$-t-thin

in-DF-night.Fs

f-n-nhar

'How many bags of flour do you use (i.e. make into bread, lit. 'do') in one (lit. 'the') night, in one (lit. 'the') the day?'

(27b) J.hal

ka-n-dir-u //

xəms.a//

sti.a

how.many

IND-1.IPF-do-P

five

six

'How many we use (lit. 'do')? Five, six.'

(28) MA

$\begin{array}{lllll}\text { sadi } & n \text {-dir-ha } & \text { bont- } i & w & \text { dak.f-fi } \\ \text { FUT } & \text { 1-do:IPF-3Fs } & \text { daughter-1s } & \text { and } & \text { DM-thing } \\ \text { 'I will make her into my daughter and so on' }\end{array}$

[C.91.1_0156]

'I will make her into my daughter and so on' 


\subsection{Caused change of location}

\subsubsection{Transfer}

While MA dar is rarely used in a 'creation' sense, a prominent function of this verb in the corpus is with an interpretation of 'transfer, caused change of location', as in (30), (31) and (32). This is not one of the uses identified for 'do' verbs cross-linguistically by Schultze-Berndt (2008), but it has a well-known parallel in (northern varieties of colloquial) German, where tun 'do' can be used in a transfer sense with a prepositional phrase indicating the location (29).

(29) German ${ }^{2}$

$\begin{array}{lllll}\text { Diese } & \text { Hose } & \text { habe } & \text { ich } & \text { kürzlich } \\ \text { this.FS.ACC } & \text { trousers } & \text { AUX.PST:1s } & \text { 1s } & \text { recently }\end{array}$

in den Schrank getan

in DF.MS.ACC wardrobe do:PCP

'These trousers I recently put (lit. 'did') into the wardrobe'

(30) MA

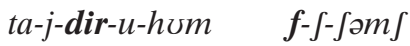

IND-3MS-do-P-3P in-DF-sun

'They put (lit. 'do') them (boxes with honey) in the sun'

(31) MA

$\begin{array}{lllll}u & k a-i-\text { dir-l-hom } & \text { l-qnabol } & \text { taht-hum } & a-s a \hbar b-i \\ \text { and } & \text { IND-3MS.IPF-do-to-3P } & \text { DF-bomb.P } & \text { under-3P } & \text { voc-friend-1s } \\ \text { 'and he throws (lit. 'does') bombs amidst them, my friend' }\end{array}$

(32) MA

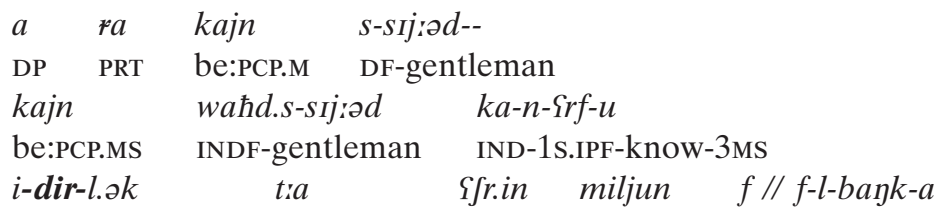

[A.06.1_0456-7]

3MS.IPF-do-3MS even/also 20 million in in-DF-bank-FS

'Ah, there is a man I know who even puts (lit. 'do') 20 Million in the bank.'

There is a verb used for the literal meaning of 'put', namely $\hbar ə t$ : which presumably would have been used if the money were actually paid into the bank. But in this case the 20 million only seemingly are placed on deposit to make it look like a 20-million-bank account. This is exactly what dar is used for: to do something to the effect of something.

The 'transfer' sense of MA dar may also underlie a more idiomatic use with the interpretation of 'broadcast'.

(33) MA

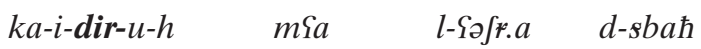

$$
\begin{aligned}
& \text { IND-3-do-P-3MS PREP DF-ten POSS-morning }
\end{aligned}
$$

'(They had some difficult programs. One (was) on Friday), they broadcast (lit. 'do') it at 10 in the morning' 


\subsubsection{Wear item of clothing}

A 'transfer, cause change of location' sense of MA dar may also explain the use of this verb in contexts of wearing - i.e. 'putting on' - an item of clothing, jewelry or ornaments, which is fairly frequent in the corpus and illustrated in (34) to (38). This link is confirmed by example (36), where the body part on which the item of clothing is worn is specified as a location. In one instance (37) the item of clothing is also left unspecified.

(34) MA

$\begin{array}{llll}l a & m a & k a-t-d i r-\int a j & \text { 3-3ol:ab.a } \\ \text { no } & \text { NEG } & \text { IND-3FS.IPF-do-NEG } & \text { DF-jellaba.FS }\end{array}$

'No, she does not wear a jellaba'

[A.06.2_0100]

(35) MA

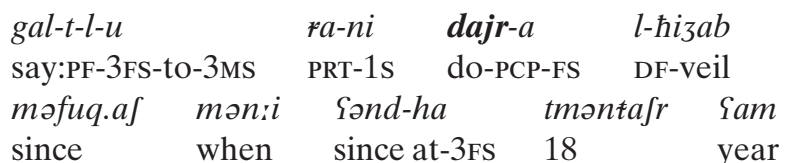

[A.06.1_0867]

'She said to him "since when do I wear (lit. 'do') the veil: since my (lit. 'her') eighteenth year"”

(36) MA

$\begin{array}{lllll}\text { n-dir } & \text { l-liga- } t & \text { djal } & \text { l-mika } & f \text {-id:- } i \\ \text { 1s.IPF-do } & \text { DF-glove-PF } & \text { POSS } & \text { DF-plastic } & \text { in-hand-1s } \\ \text { Pan ma } & \text { nə-qdor- } \int & & & \\ \text { 1s } \quad \text { NEG } & \text { 1s.IPF-can-NEG } & & \end{array}$

[C.91.1_0447]

'But that I do the cooking [as opposed to doing the cleaning] and) put (lit. 'do') plastic gloves on my hand, I can't do (that)'

(37) MA

wahd.d-dori $\quad$ dajr $\quad$ Sond-u

INDF-boy do:PCP.MS at-3Ms

'One boy (is/works) with him wearing (lit. 'doing', implicit: 'glasses')'

(38) MA

$\begin{array}{lll}\text { l-Pinsan } & \boldsymbol{t a} \boldsymbol{a} \text {-j-dir } & \text { l-hən:a } \\ \text { DF-human.being } & \text { IND-3MS.IPF-do } & \text { DF-Henna }\end{array}$

[C.91.1_0656]

'One usually puts on Henna (at the occasion of a celebration)'

When it comes to putting on items of clothing or jewelry and the like, the direct object may again be replaced by a prepositional object as discussed in section 2.1, to express overdoing things (39), the exaggeration being phonetically expressed by the emphatic lengthening of the vowel in dajr [de:r].

(39) MA

$\begin{array}{llll}\text { gal-l-i } & k i & \text { dajr [de: } \boldsymbol{r}] & \text { b-d-dhub-at } \\ \text { say:3MS.PF-to-1s } & \text { how } & \text { do:PCP.MS } & \text { with-DF-gold.P-FP }\end{array}$

[A.04.10_0567]

'He told me how he decked himself out with gold'

Again, this is not a use that had been identified in the cross-linguistic survey of SCHULtZe-BERndT (2008), and we are not aware of cross-linguistic parallels, although their 
existence does not seem unlikely. In German, for instance, the GAV 'tun' is used with a locative preverb for putting on jewelry or colour (40).

(40) German $^{3}$

$\begin{array}{llllll}\text { kann } & \text { eh } & \text { ned } & \text { viel } & \text { schmuck } & \text { drantun ... } \\ \text { can:[1]s.PRS } & \text { DP } & \text { NEG } & \text { much } & \text { jewelry } & \text { put.on (lit. 'do' on).INF } \\ \text { 'I cannot put on too much jewelry (because I have such a bad allergy to nickel)' }\end{array}$

\subsection{Mimetic verb}

The term "mimetic verb" has been used by GüLDEMANN (2008) to cover two crosslinguistically well attested uses of generalized action verbs, as quotative verb and as verbaliser with sound-symbolic elements (variously termed 'onomatopoeia', 'ideophones' or 'sound-symbolic adverbs') - often iconic representations of noises. Moreover, the same verb is often used to incorporate non-verbal mimetic expressions - i.e. gestures - into speech, also included in the domain of mimesis by GüLDEMANN (2008). Both functions are illustrated with Jaminjung examples in (41). In German, the GAV machen can be used in the second but not the first function.

(41)

$$
\begin{aligned}
& \text { Jaminjung } \\
& \text { “ba-rum" gani-yu=nu } \\
& \text { IMP-come } 3 \mathrm{~s}>3 \mathrm{~s}-\mathrm{do}=3 \mathrm{~s} \text {.OBL } \\
& \text { "“Come" she said (lit. 'she did') to him' }
\end{aligned}
$$

\begin{tabular}{|c|c|c|c|}
\hline $2 \mathrm{a}$ & Und & auf & einmal \\
\hline
\end{tabular}

(42) German 'and suddenly it went "splash",

$\begin{array}{lll}\text { Da hat } & \text { er so } & \text { gemacht } \\ \text { then AUx:3s.PST he do.like.that } & \text { PCP:do.PST } \\ \text { (accompanied by gesture) } & & \\ \text { 'then he went like that' } & \end{array}$

MA behaves like German in that dar 'do' is used as a verbaliser with sound-symbolic elements but not as a quotative verb. Instead, a dedicated 'say' verb is used with verbal quotations. Examples of the mimetic use of dar are given in (43) to (46). Note in particular

\begin{tabular}{|c|c|c|c|}
\hline$X X X$ & $k a-i-b q a$ & $i$-dir-l-ək & $d i k-\boldsymbol{t}-\boldsymbol{t}-\boldsymbol{a} q$ \\
\hline [unintelligible] & IND-3MS.IPF-stay & 3MS.IPF-do-to-2s & DM.FS-DF-[taq \\
\hline
\end{tabular}
that in (45), the subject of the mimetic event is inanimate, i.e. there is no component of control or agentivity associated with the use of dar here.

3 http://www.spin.de/forum/msg-archive/308/2008/06/50976, accessed 9. September 2012.

[A.06.1_0676] 
(44) MA

u dor-t-l.ha hak:a

[A.06.2_0397]

and do-1s.PF-to-3Fs thus

'and he did to her like this (accompanied by gesture)'

(45) MA

ka-j-dir b.hal l-bl:ot[bot:ut] mn:i ka-j-tib hak:a

IND-3MS-do like DF-acorn when IND-3MS-ripen thus

'They (apples) go like an acorn when it ripens, like this (i.e. they burst)'

(46) MA

dar-u-l.ha [qrab:]

[F.92.2a_0214]

do.PF.3-P-to-3Fs grab

'they grabbed it' (lit. the went to her [the money] [qrab:]' (imitation of sound of dog grabbing meat)

\subsection{Collocations with loanwords}

A further frequent function of generalised action verbs, which may well be related to the mimetic domain, is that of verbaliser with loanwords; this has been recognised as one of the important functions of 'do' verbs in the literature (see WoHLGEMUTH 2009 for an overview and references) and is related to the observation that the borrowing of verbs as verbs is cross-linguistically marked.

In the examples of collocations involving dar found in the corpus, the borrowings (from French) are nominal in the donor language, and themselves enter into collocations with faire 'do' (faire en marche, faire la ménage, faire l'enquête, faire l'autostop). However, speakers confirmed that in MA, loan words are productively verbalised with dar. Other Arabic varieties, in any case Modern Standard Arabic which is predominantly written, employ morphological means of verb formation to create new verbs, such as MSA istansaxa 'photocopy' from nusxa 'exemplar, copy' or EA sawwar from surra 'picture' (compare the MA example in (24) above).

(47) MA

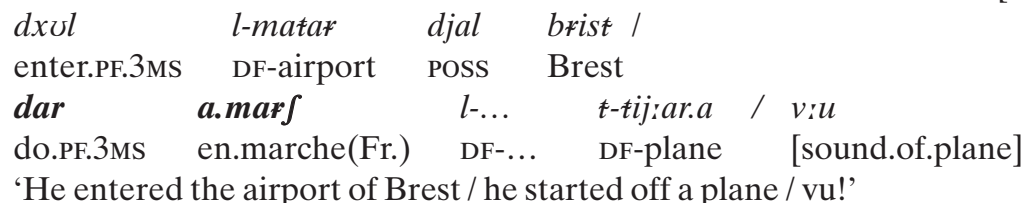

(48) MA

bo-l-liga- $t \quad$ Pila bsi-t $\quad n$-dir l-minaz

with-DF-glove-FP if/when want-1s.PF 1s.IPF-do DF-ménage

'With gloves (I work) when I want to do the household (i.e. cleaning)'

(49) MA

kif dar-u mia-h l-unkit

[A.06.1_0169]

how do.PF.Ms-P with-3Ms DF-enquête(Fr)

f.nu gal-l-hom

what say.PF.3Ms-to-3P

'When they did the interrogation with him, what did he tell them?' 
(50) MA $\begin{array}{lll}\text { xəs:-ək } & t \text {-dir } & \text { otostup } \\ \text { be.necessary:3MS.PF-2S } & \text { 2S.IPF-do } & \text { hitchhike }\end{array}$ '(Some people told me:) "You have to hitchhike",

\subsection{Manifestation of quality}

As already indicated above, and argued in detail in Schultze-Berndt (2008), generalised action verbs do not always express an action in the narrow sense, i.e. are not always agentive in nature. Rather, they may be involved in expressions of events that occur without the involvement of an agent ('happen') and also in expressions of change of state ('become') or of a manifestations of a quality, condition or state ('be, exhibit property') the latter illustrated here with examples from Ewe and Jaminjung.

(51) Ewe

é-wo kél ba / nogoo / sue

3s-do sand mud round small

[Амека 1994: 71]

'it is sandy/muddy/round/small' (lit. 'it does sand etc.')

(52) Jaminjung

gugu marring gan-unggu-m

water bad 3s $>3 \mathrm{~s}$-say/do-PRs

'The tap is broken' (lit. 'The water does bad')

MA dar is found in a single, possibly idiomatic, expression of change of state in the corpus, which due to the etymological origin of dar in a root meaning 'turn' (see section 1) is however not unexpected.

$\begin{array}{lll}\text { MA } & & \\ \text { dar } & \text { tolt.afr } & \text { Sam } \\ \text { do.PF.3ms } & 13 & \text { year } \\ \text { 'He turned 13 years' } & \end{array}$

[A.06.1_0145]

The verb is attested, albeit to a limited extent, in the function of manifestation of a quality, i.e. in a copula-like use. One such expression - example (54) - was tested with 241 informants in Morocco in spring 2012 by SANDRA Ziagos using a questionnaire. The overwhelming majority reported to hear people use the expression and 146 informants said that they actually use it. Interestingly, this item of the questionnaire showed a difference between Casablanca and Fes. It seems that the expression is more widespread in Casablanca.

(54) MA

$$
\begin{array}{ll}
\text { dajr } & \text { la-bas } \\
\text { do:PCP.MS } & \text { NEG-harm } \\
\text { 'he is well(-off)' }
\end{array}
$$

[Survey data SANDRA Ziagos]

Further examples from the corpus and from elicitation point to a relatively restricted occurrence of such 'copula'-like uses of dar. In particular, it appears to be restricted to handful of idiomatic, lexicalized calques from Tamazight, where this function of the corresponding generalised action verb is productive (AA, p.c., Maarten Kossmann, p.c.). An example elicited with a bilingual speaker is provided in (55) and (56). 
(55) MA

\section{dajr}

do:3MS.PF

l-mtawwor

'he is intelligent (lit. 'he does intelligent')

(56) Tamazight

$\begin{array}{ll}i \text {-zu } & \text { Pa-mftor } \\ \text { 3MS.PF-do } & \text { DF.MS-intelligent }\end{array}$

'he is intelligent' (lit. 'he does intelligent') [elicitated with AA]

[elicited with AA]

Available corpus examples are few and not unambiguous. They also show the close link between performing and action and exhibiting a property, at least with animate (in particular human) subjects. The use of the 'do' verb in (57) could interpreted as 'doing like a commander, displaying the attitude of a commander'; however in the discourse context the sentence is simply a statement about the profession and location of the speaker's uncle at the time, and in this respect the 'do' verb does have a copula-like function. Rather than being anomalous, these kinds of uses can be analysed as constituting the semantic link between an 'action verb' use and a 'copula use' of a single verb which otherwise seems rather puzzling.

$$
\begin{aligned}
& \text { MA } \\
& w \text { hadak xal-i kan ta-j-dir } \\
& \text { and DM.MS uncle-1s be.3MS.PF DUR-3MS.IPF-do } \\
& \text { komandar djal l-Səskər } \\
& \text { commander POSS DF-army } \\
& \text { 'and this uncle of mine, he was (lit. 'did/made') a military commander, (in T [a place] } \\
& \text { near Marrakesh)' }
\end{aligned}
$$

A crucial feature of an unambiguous 'manifestation, exhibition of property' use of a generalised action verb would be its occurrence with inanimate subjects, i.e. subjects which clearly cannot be agentive. It is not clear to us whether Moroccan Arabic allows such uses; this is clearly an area for further exploration.

\section{The semantic range of dar in typological perspective}

In this paper, we investigated the range of functions of the verb dar in Moroccan Arabic, which serves as a generalised action verb (a 'do' verb with unspecified actions) but which like corresponding verbs cross-linguistically - has a wider range of functions.

In Figure 1, the uses of Moroccan Arabic dar 'do' are summarised in the form of a semantic map. The Semantic Map approach is based on the idea that the comparison of the functional range of (grammatical or lexical) morphemes showing some semantic overlap will reveal a network of functions and the degree of their semantic affinity. Thus, if we find that a given morpheme never has two specific functions $\mathrm{A}$ and $\mathrm{D}$ unless it also has one or more additional functions $\mathrm{B}$ and $\mathrm{C}$, we can state that $\mathrm{A}$ and $\mathrm{D}$ are more distantly related, and $\mathrm{B}$ and $\mathrm{C}$ are intermediate functions in the network (cf. van DER AUwERA \& Plungian 1998). Ideally, such a semantic map will have predictive value in the corresponding morpheme in any additional language will also cover a contiguous region in the map; in the process of adding languages to the sample, the semantic map may of course undergo revisions. 
Figure 1 is based on the semantic map of generalised action verbs proposed in SCHULTZEBERNDT (2008). The arrangement of the different functions in the map is compatible with the functional range of the generalised action verbs from the five languages considered in that study (Ewe, Samoan, Jaminjung, Chantyal, and Kalam), but some functions have been added to account for the semantics of Moroccan Arabic dar and səwwəb. For reasons of space, the languages from the original study (except for Jaminjung) are not being displayed here, but in order to provide points of comparison, German and English have been added. Note however that purely grammatical functions ('do' support) as well as the emphatic use of 'do' verbs - as found in English - have been left out of consideration here since we are only interested in the semantic range of the verbs as main verbs or in collocations.

As discussed in the previous section, in addition to its use as a generalised action verb (section 1), Moroccan Arabic dar is used in a range of agentive collocations (ACT) with an action nominal (section 2.1). An interesting property of Moroccan Arabic in this respect is that there exist productive variants of the (expected) construction with an action nominal as a direct object where the action nominal occurs as the complement of a preposition rather than as a direct object.

A very productive and frequent use of $d a r$ 'do' is in a sense of spatial transfer (referred to as 'caused change of location' in section 2.3, but represented as PUT in the semantic map for reasons of space). This use seems to be linked to its etymological origin, the causative verb ?a-da:ra 'turn (trans.), twist'. It was suggested that this use is also linked to a more specialised use in expressions of wearing items of accessory clothing such as glasses or a veil (not included in the map), and, by metonymy, to a use in a sense of 'transformation, turning something into something else' (TRANSFORM).

In line with cross-linguistic findings, MA dar also appears as a verbaliser with "mimetic" elements such as conventionalised sound-symbolic elements, sound imitations, or gestures (section 2.4). However, the function of quotative verb that is often also attested for such verbs is absent from MA.

The function of verbaliser with loan words, discussed in section 2.5 , can possibly be linked to this mimetic function, but was not included in the map because it is based on etymological origin rather than semantic type of the complement of the 'do' verb.

Unlike 'do' verbs in many other languages, Moroccan Arabic dar is not generally used as a verb of creation (CREATE) although a few such uses are attested (see section 2.2); instead, the verb səwwəb is used in this function and (less frequently) also as a generalised action verb. Neither is dar 'do' used in a more grammaticalised function, i.e. as a productive causative marker (CAUS). As in other Arabic varieties, causativisation is achieved either by lexical or by morphological means in Moroccan Arabic. Functions which are also not covered by Moroccan Arabic dar - but which are attested for generalised action verbs cross-linguistically - are the function of verbaliser for non-agentive events (HAPPEN) and the verb in expressions of manifestations of emotions (FEEL). The function of inchoative verb (INCHOAT) was only attested in one idiomatic expression 'turn X years'.

Finally, dar is marginally attested in a copula-like use (MANIFEST) with property predicates. While not unusual cross-linguistically, this use is most likely explained as a calque from Tamazight, which would also account for its low frequency in the corpus and variable acceptability in a questionnaire elicitation. It is at the "margins" of the semantic map functions that are not frequent in the corpus - that the limits of a corpus-based investigation become apparent and a more fine-grained picture than the one presented here could 
certainly be obtained with a systematic, fieldwork-based investigation, including an investigation of the effect of bilingualism in MA and Tamazight/Berber on the use of convergent structures.

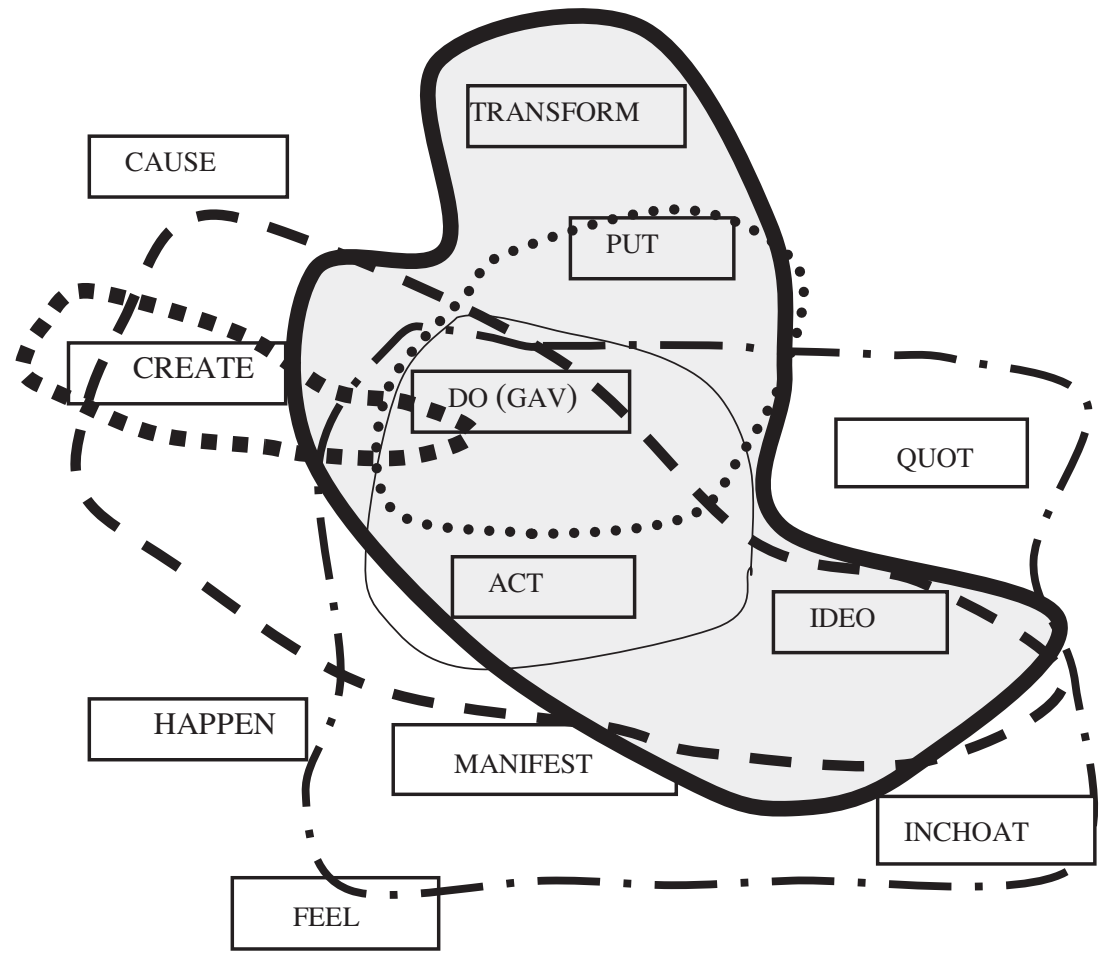

Moroccan Arabic dar

$\square \square \square \square \square \square \square \square \square$

Moroccan Arabic s uweb

English do

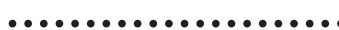

German tun

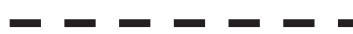

German machen

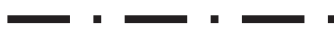

Jaminjung -yu(nggu)

Figure 1: Semantic map of 'do'-verbs in English, German, Jaminjung and Moroccan Arabic 


\section{Potential further research questions}

Our study raises a number of questions for further research. Evidently, other Arabic varieties use equivalent verbs for similar functions. A comparison of 'do'-verbs in Eastern and Western Arabic varieties would shed some light on how the GAV functions have developed in a couple of closely related languages. Furthermore, the data could also be looked at in comparison to Modern Standard Arabic (MSA), which is predominantly written, while the various Arabic vernaculars (MA, EA, IA etc.) are almost exclusively spoken varieties. Such a comparison could provide evidence for the hypothesis that semantically generic verb like 'do' are more frequent in orate genres, whereas in literate genres more specific verbs are employed instead. Also mimetic use (see 2.4.) is probably very restricted in literate genres.

As already mentioned, another interesting aspect to be pursued in further research is the degree of convergence/divergence between Berber and MA in the use of generalized action verbs. This specific question would also benefit from a comparison with the Eastern Arabic varieties that are not in contact with Berber languages. A case in point in that respect seems to be the 'copula'-function use in MA which apparently is developing in the specific contact situation of MA/Berber in Morocco.

\section{Abbreviations}

$\begin{array}{llll}\text { ACC } & \text { accusative } & \text { M } & \text { masculine } \\ \text { ASP } & \text { aspectual marker } & \text { MS } & \begin{array}{l}\text { masculine singular } \\ \text { negation }\end{array} \\ \text { AUX } & \text { auxiliary } & \text { NEG } & \text { nominative } \\ \text { DAT } & \text { dative } & \text { NOM } & \text { oblique case } \\ \text { DF } & \text { definite article } & \text { OBL } & \text { plural } \\ \text { DM } & \text { demonstrative } & \text { P } & \text { participle } \\ \text { DP } & \text { discourse particle } & \text { PCP } & \text { perfective } \\ \text { DUR } & \text { durative } & \text { PF } & \text { possessive } \\ \text { FP } & \text { feminine plural } & \text { POSS } & \text { potential modality } \\ \text { FS } & \text { feminine singular } & \text { POT } & \text { preposition } \\ \text { FUT } & \text { future tense } & \text { PREP } & \text { present tense } \\ \text { IMP } & \text { imperative } & \text { PRS } & \text { presentational } \\ \text { IND } & \text { indicative } & \text { PRT } & \text { past tense } \\ \text { INDF } & \text { indefinite article } & \text { PST } & \text { singular } \\ \text { INF } & \text { infinitive } & \text { S } & \text { vocative } \\ \text { IPF } & \text { imperfective } & \text { VOC } & \end{array}$

Eva Schultze-Berndt

School of Arts, Languages and Cultures The University of Manchester Oxford Road Manchester, M13 9PL UNITED KINGDOM eva.schultze-berndt@manchester.ac.uk
Dina El Zarka

Karl-Franzens-Universität Graz Institut für Sprachwissenschaft Merangasse 70 A - $8010 \mathrm{Graz}$ AUSTRIA dina.elzarka@uni-graz.de 